\title{
A healthy degree of suspicion: A discussion of the implementation of transmission based precautions in the emergency department
}

\author{
Peta-Anne Zimmerman (RN CICP DPH) ${ }^{a, b, *}$, Matt Mason (RN BN \\ GradDipRemoteHealthPractice MAdvancedPrac(Infection Control) MRural Health) ${ }^{\mathrm{C}}$, \\ Elizabeth Elder (RN BN BA MAdvancedPrac(Emergency Nursing) MN(Hons)) ${ }^{\text {a }}$
}

\author{
a School of Nursing and Midwifery, Griffith University, Australia \\ b Gold Coast Hospital and Health Service, Australia \\ ' School of Nursing, Midwifery and Paramedicine, University of the Sunshine Coast, Australia
}

\section{A R T I C L E I N F O}

\section{Article history:}

Received 17 December 2015

Received in revised form 10 March 2016

Accepted 29 March 2016

\section{Keywords:}

Emergency department

Triage practices

Transmission based precautions

Healthcare associated infections

Infection control

\begin{abstract}
A B S T R A C T
Background: Emergency department (ED) presentations have increased significantly domestically and internationally. Swift identification and implementation of transmission based precautions (TBP) for patients known or suspected of having an epidemiologically important pathogen is important. ED staff, particularly triage nurses, are pivotal in detecting and preventing infection, including healthcare associated infections (HAI).

Methods: MEDLINE, CINAHL, PubMed and Ovid were searched for articles published between 2004 and 2015 using key search terms: infection control/prevention and emergency department(s), triage, and transmission based precautions and emergency department(s), and triage, to identify common themes for discussion. Systematic review/meta-analysis was not in the scope of this exploration.

Findings: Themes were identified relating to HAI and ED practices and grouped into: assisted detection of conditions for which TBP is required, ED and TBP, mass-causality event/bioterrorism/pandemic/epidemic, infection control not TBP and multi-resistant organisms not TBP. The literature is heavily influenced by worldwide epidemic/pandemics and bioterrorist risks resulting in increased awareness of the importance of swift identification of syndromes that require TBP, but only in these situations.

Conclusion: Implementation of appropriate TBP, changing triage practices, training and measures to assist decision-making could assist in preventing HAI in the ED context. A systematic quantitative review of the literature is recommended to guide practice change research.
\end{abstract}

(C) 2016 College of Emergency Nursing Australasia. Published by Elsevier Ltd. All rights reserved.

\section{Introduction}

Prevention and control of healthcare associated infections (HAI) is one of the greatest challenges confronting healthcare providers and clinicians worldwide. Emergency departments (ED) have a significant role in identification, triage and application of proven infection prevention and control (IPC) measures to curb the risk of transmission of communicable disease within the healthcare setting. Best practice indicates this is achieved through the swift identification and implementation of transmission based precautions (TBP) for patients who are known or suspected of having an epidemiologically important pathogen. Emergency departments are often viewed as healthcare safety net providers with the num-

\footnotetext{
* Corresponding author at: Office 2.47, Clinical Sciences 2 (G16), Parklands Drive, Southport, QLD 4215, Australia. Tel.: +61 (0)7 55528780.

E-mail address: p.zimmerman@griffith.edu.au (P.-A. Zimmerman).
}

ber of ED presentations steadily increasing over recent years [1,2]. This added pressure from both the community and primary care providers can potentially further strain a compromised or inadequate triage system and place healthcare worker and patient safety in jeopardy.

Transmission-based precautions are IPC practices implemented for the care of patients who are known or suspected to be infected with a pathogen that is transmitted by contact (direct or indirect), droplet or airborne routes [3,4]. These precautions are subsequently divided into three types: (1) contact, (2) droplet and (3) airborne precautions, or a combination of these. Transmissionbased precautions are always implemented in addition to standard precautions, which are IPC practices in place for all patients, regardless of known or suspected infectious status. In acute care settings, TBP require a combination of:

- appropriate personal protective equipment (based upon route of transmission) 
- patient-dedicated equipment

- single room accommodation or cohorting of patients

- appropriate air handling systems

- specific environmental cleaning requirements

- restricted transfer and/or movement of patients within and between facilities [3].

Timely implementation of TBP is aimed at reducing opportunities for infectious agents to be spread via their specific transmission route. These precautions are therefore warranted when there is a potential for a patient to be infected, or colonised in some cases, with a relevant pathogen $[3,4]$. Community outbreaks of infectious disease can be easily amplified in the healthcare setting if wellestablished IPC principles and policies are not being practiced. This is particularly true of respiratory pathogens such as respiratory syncytial virus (RSV) and Bordetella pertussis or those spread through airborne transmission such as measles and tuberculosis. In late 2003 the world saw an outbreak of a new respiratory virus causing illness and mortality in both patients and health care workers. By mid-2004 the pathogen, severe acute respiratory syndrome coronavirus (SARS-CoV), was identified and the world prepared for a pandemic response. The year 2009 saw a novel influenza A (H1N1) strain causing significant illness across the globe, resulting in a pandemic [5]. In 2014 the largest known outbreak of Ebola virus disease (EVD) occurred (and is still continuing) in West Africa with devastating human, economic and societal effects in that region. With the recent spread of Middle Eastern respiratory syndrome coronavirus (MERS-CoV) in the Asia-Pacific region it is timely to consider how prepared EDs are to recognise presenting infectious diseases and implement the appropriate IPC precautions.

In Australia IPC policies and principles are in place as required through the accreditation of health facilities, however compliance with these appears to not be routine during normal provision of care $[6,7]$. Therefore when the need to step-up precautions occurs there is a limited baseline level of practice and compliance to build from. For example, hand hygiene is widely recognised as a foundation of infection prevention. The latest national compliance rate for hand hygiene in Australia is $82.2 \%$ across all healthcare workers [8]. Variation exists between professions with nurses and midwives at $84 \%$ and medical staff at $68.9 \%$ with other healthcare workers (such as allied health professionals and ancillary staff) in between. With baseline compliance at this level, one of the most basic aspects of IPC, there is little reason to suspect that this would not contribute to healthcare workers becoming ill.

Similarly the compliance with transmission based precautions is often less than ideal. High patient volume in acute care limits the ability to place patients suspected of requiring single rooms in these until a diagnosis is confirmed. This creates a potential reservoir of infection for both patients and healthcare workers alike. It has also been shown that health care workers can be reluctant to implement transmission based precautions until a diagnosis is confirmed due to perceived and real imposts on time and resources, plus administrative patient flow pressure. Human factors may lead to a situation where the healthcare workers are cognitively overloaded and as their regular practice may be less than $100 \%$, small breaches can occur that they themselves do not identify as breaches. The 'To Err is Human' report in 2000 identified the gap between what is recommended practice and actual practice [9]. Consistently this gap is identified in the application of transmission based precautions as well as other infection prevention strategies potentially leading to health care acquired infections in patients and health care workers [10]. The director of the Centers for Disease Control and Prevention (CDC), Dr Tom Frieden was recently quoted as saying

"There are 75,000 deaths each year from infections spread in hospitals in the U.S. We know no matter how good our recommendations for hand washing and personal protective equipment are, we have to have a large margin of safety for how they will actually be implemented in the field" [11] suggesting that the CDC acknowledges that clinicians are not always going to follow IPC guidelines, and this is largely unintentional. Yet, accepting standards that put patients, staff and visitors at risk goes against legal and ethical responsibilities of health care staff. This reinforces the need for practices to be second nature for health care workers to ensure that as the potential for harm increases small errors do not have fatal consequences. The practice of infection prevention and control is not an optional extra for clinical practice and patient management, it is essential to both patient and healthcare worker safety. The ability to recognise infectious conditions and implement the appropriate TBP at all times and not only at times of heightened awareness is therefore particularly relevant in the ED context.

\section{Methods}

To explore and discuss the current state of knowledge in this area of interest, an exploration of the literature was performed to provide a narrative. A systematic review or meta-analysis was not performed as this is an exploratory review of the common themes within this topic, to identify directions for further research. This included a search for works published in English available via MEDLINE, CINAHL, PubMed and Ovid, for the years 2004 through to September 2015. Search terms included; infection control/prevention and emergency department(s), triage, and transmission based precautions and emergency department(s), and triage. The date range selected was to take into consideration the effect that recent epidemic/pandemics may have had on ED practice. Identified articles were used to select additional key terms for further searches. Other relevant articles were identified from the bibliographies of these papers.

Articles and documents sought in the review were those that examined the identification of conditions caused or likely to be caused by important pathogens and subsequent implementation of appropriate IPC measures at triage and during admission to the ED. More specifically the search was to identify literature that: examined the implementation of TBP upon presentation and admission to the ED to prevent transmission to both health care workers (HCW) and other patients/visitors; and relevant specifically to pathogens transmitted via the contact, droplet and airborne routes and their associated IPC practices in non-emergency (i.e. not mass casualty, epidemic, pandemic, or bioterrorism) situations in the ED setting. Conference abstracts were excluded from the search.

\section{Results}

A total of 3572 articles were discovered through the method described. After the exclusion process described above the remaining articles $(n=41)$ were then organised into categories to identify common themes within the literature.

\section{Discussion}

\section{A healthy degree of suspicion}

The importance of rapid implementation of TBP in the ED setting for the protection of patients and HCW against infectious diseases is well represented in the literature [5,12-19]. Emerging and reemerging infectious diseases, international travel, mass gatherings, incomplete vaccination, overpopulation, urbanisation all place pressure upon contemporary healthcare and the ability to contain infectious disease $[5,13]$. These issues combined with increasing ED presentations of patients with non-emergent concerns, noncommunicable disease and a co-morbid ageing population indicate 
there is increased and arguably dangerous pressure upon ED staff to provide swift triage and care to patients $[18,20]$. Regardless of this pressure, however, there is an imperative for the appropriate application of TBP in this setting. Failure to identify a significant communicable condition and the subsequent implementation of TBP has led to a number of infectious disease outbreaks to occur amongst patients, staff and visitors both after admission to the ED and whilst in the waiting room $[14,21-28]$. The most obvious of these would be the reported transmission of SARS and pandemic influenza, however, infectious diseases such as gastroenteritis, scabies, tuberculosis, other airborne organisms and pertussis are well represented $[14,21-23,25,27,29,30]$. Emergency department clinical staff, particularly those who have first contact with presenting patients, must be familiar with common infectious disease as well as those that are emerging or re-emerging locally and globally $[13,20,31,32]$.

The identification of potential infection or colonisation of patients with an epidemiological important microorganism in the ED is problematic [33,34]. Current literature suggests a gap in proficiency for triage and ED staff when identifying infectious diseases [35-40]. Recommendations have previously been made by the European Network of Infectious Diseases as to the requirements of HCW training in the recognition of patients with a suspect condition with particular importance on triage and ED staff [41]. The adoption and implementation of these requirements has not been reported and similarly it must be noted that the knowledge of infectious diseases and relevant training for staff in the Australian context has not been described.

It has been identified that triage protocols should not only include the normal assessment of urgency or severity of disease but also the risk of disease transmission that the patient poses both in the waiting room and in the ED proper [20]. These procedures should be in place at all times, not just in times of pandemic, mass casualty events, mass gatherings or other heightened awareness $[20,35,42]$. In doing so the risk of HAI is reduced. To assist it is recommended that based on the risk assessment of disease transmission, empiric application of TBP should be utilised [5,20,41,43].

The application of TBP where triage practices are observed in real time is an area of limited research [44]. Related areas such as application of airborne precautions have been studied but are often retrospective and use document/database reviews or self-reporting as data collection means [20,45-47]. These can be problematic due to documentation inaccuracies or bias in self-reporting. This indicates there is a need to undertake more rigorous real time observation research to document current practices.

\section{Assisted detection of infectious diseases}

Syndromic surveillance and syndromic identification methods are well established and are designed to identify key features of a patient presentation that may assist in identification of infectious risk such as: chief complaints, signs, symptoms, travel history, demographics, occupation $[48,49]$. Such practices were well utilised during the SARS and various influenza outbreaks and led to quick containment and treatment of the presenting infection $[24,50]$. Syndromic surveillance methods primarily focus upon the early symptoms of an infectious disease and can be used in conjunction with demographic data to identify risk [51,52]. Most syndromic surveillance systems currently exist to identify bioterrorism or epidemic/pandemic events, but it can be equally utilised to identify patients who present to ED with an infectious disease of local importance [52]. Syndromic surveillance must occur in real time to assist triage and ED staff in applying appropriate TBP to prevent the spread of infection.

Computerised systems are a useful adjunct to assist clinical decision making. Gerbier-Colomban and colleagues introduced such a system that used syndromic algorithms to analyse structured and unstructured data from the ED electronic record to identify patients with potential infectious diseases [51,52]. The results indicated the system was successful in detecting respiratory (specificity $82.37 \%$ ) and cutaneous (specificity 95.93\%) syndromes, but was less reliable for gastrointestinal syndromes [51]. The main problem with this project was that it focused on patients admitted to the facility and did not provide real time analysis to ED staff in order for them to institute appropriate TBP.

Successful application of TBP in a time appropriate fashion has been identified in a number of studies. This real time application of TBP has required the real time detection of potentially infectious patients $[20,41]$. The successful studies have shown that having triage and ED staff well trained in the identification of infectious diseases with a high index of suspicion and decision making algorithms embedded in the triage assessment is an important way to achieve this $[36,38,53]$. The use of point of care testing (POCT) devices can further improve these practices.

Point of care testing using rapid tests at the bedside, or in the ED has been reported by a number of studies to facilitate the detection and swift treatment of patients infected or colonised with an epidemiologically important pathogen, such as influenza, respiratory syncytial virus (RSV) and group A Streptococcus (GAS) [54,55]. Therefore these tests can be used to validate the use of TBP for patients who are identified as requiring them through syndromic surveillance or the cessation/modification of TBP if the syndromic assessment is not substantiated [55]. In doing this a reduction in ED bed pressure can be achieved as patients are able to be cohorted and/or accommodated via other appropriate mechanisms [54,55]. Unfortunately implementation of POCT in many EDs is not seen as feasible due to funding and space requirements. Studies into the cost/benefit of such systems are required and should include the offset costs of reduced ED bed pressure and increased through put.

\section{Considerations for further research}

The literature strongly supports that providing ED staff with up to date education in recognising potentially infectious presentations in their patients is important. Similarly the ability to correctly and efficiently apply TBP once a requirement to do so is identified is vital in reducing the potential spread of disease within the ED. Looking at alternate methods of education needs to be considered, such as the use of popular culture which has been shown to increase engagement with educational activities and provide staff with a safe environment to make mistakes [56,57]. Active real time research into the application of TBP in the ED is an area well suited to this particular type of activity.

\section{Conclusion}

It is clear from the literature that the rapid identification of potentially transmissible conditions and the application of the appropriate TBP is essential to both patient and HCW safety. There are pressures and imperatives that make this difficult within the ED environment and this, in association with a gap in infectious disease detection proficiency, can lead to outbreaks of infectious disease both inside health facilities and the community at large. Assisting triage and ED staff through training and real time syndromic surveillance methods, including POCT where applicable, can facilitate better outcomes. There are however areas in the research, such as observation of the application of TBP at triage and in the ED setting generally, that warrant further investigation. While undertaking this narrative review of the literature it has become clear that a more robust systematic quantitative literature review is required. Despite this, a paucity of evidence has been found around the appropriate application of TBP in the ED setting at times when heightened awareness is not occurring. 


\section{Provenance and conflict of interest}

The authors declare that they have no conflict of interest. This paper was not commissioned.

\section{Funding}

None declared.

\section{References}

[1] Hoot NR, Aronsky D. Systematic review of emergency department crowding: causes, effects, and solutions. Ann Emerg Med 2008:52:126-36.

[2] Australian Institute of Health and Welfare. Australian Hospital Statistics 2010-11; 2012. Available at http://scholar.google.com/ scholar?hl=en\&btnG=Search\&q=intitle:Australian+hospital+statistics\#5.

[3] National Health and Medical Research Council. Australian Guidelines for the Prevention and Control of Infection in Healthcare. Commonwealth of Australia; 2010. Available at http://www.legislationreview.nhmrc.gov.au/_ files_nhmrc/publications/attachments/cd33_infection_control_healthcare.pdf.

[4] Health Care Infection Control Practices Advisory Committee. Guideline for Isolation Precautions: Preventing Transmission of Infectious Agents in Healthcare Settings. Centers for Disease Control and Prevention; 2007. Available at http://www.cdc.gov/ncidod/dhqp/pdf/isolation.pdf.

[5] Liang SY, Theodoro DL, Schuur JD, Marschall J. Infection prevention in the emergency department. Ann Emerg Med 2014,

http://dx.doi.org/10.1016/j.annemergmed.2014.02.024

[6] Valim MD, Marziale MHP, Richart-Martinez M, Sanjuan-Quiles A. Instruments for evaluating compliance with infection control practices and factors that affect it: an integrative review. J Clin Nurs 2013;1502-1519, http://dx.doi.org/10.1111/jocn.12316.

[7] Australian Commision on Safety and Quality in Health Care. Safety and Quality Improvement Guide Standard 3: Preventing and Controlling Healthcare Associated Infections. Australian Government; 2012.

[8] Hand Hygiene Australia. National Data Period One 2015; 2015. Available at http://www.hha.org.au/LatestNationalData.aspx.

[9] Maurette P. To err is human: building a safer health system. Ann Fr Anesth Reanim 2002;21.

[10] Jessee MA, Mion LC. Is evidence guiding practice? Reported versus observed adherence to contact precautions: a pilot study. Am J Infect Control 2013;41:965-70.

[11] Park A. Here's what U.S. health experts learned from ebola one year later. Time 2014. Available at http://time.com/4047029/ebola-lessons-one-year-later/.

[12] Weber DJ, Rutala WA, Schaffner W. Lessons learned: protection of healthcare workers from infectious disease risks. Crit Care Med 2010;38:S306-14.

[13] Zyga S, Zografakis-Sfakianakis M. Emerging and re-emerging infectious diseases: a potential pandemic threat. Heal Sci J 2011;3:159-68.

[14] Quach C, Rn MM, Mcgeer A, Li L, Simor A. Risk of infection following a visit to the emergency department: a cohort study. CMAJ 2012;184

[15] Petrosillo N, Puro V, Di Caro A, Ippolito G. The initial hospital response to an epidemic. Arch Med Res 2005;36:706-12.

[16] Lowery-North DW, Hertzberg VS, Elon L, Cotsonis G, Hilton SA, Vaughns 2nd $\mathrm{CF}$, et al. Measuring social contacts in the emergency department. PLOS ONE 2013;8:e70854.

[17] Harding AD, Almquist LJ, Hashemi S. The use and need for standard precautions and transmission-based precautions in the emergency department. J Emerg Nurs 2011;37:367-73, quiz 424-5.

[18] Goins WP, Talbot HK, Talbot TR. Health care-acquired viral respiratory diseases. Infect Dis Clin N Am 2011;25:227-44.

[19] FitzGerald G, Jelinek GA, Scott D, Gerdtz MF. Emergency department triage revisited. Emerg Med J 2010;27:86-92.

[20] Fusco FM, Schilling S, De Iaco G, Brodt HR, Brouqui P, Maltezou HC, et al. Infection control management of patients with suspected highly infectious diseases in emergency departments: data from a survey in 41 facilities in 14 European countries. BMC Infect Dis 2012;12:27.

[21] Centers for Disease Control and Prevention. Novel influenza A (H1N1) virus infections among health-care personnel - United States, April-May 2009. MMWR Morb Mortal Wkly Rep 2009;58:641-5.

[22] Escombe AR, Huaroto L, Ticona E, Burgos M, Sanchez I, Carrasco L, et al. Tuberculosis transmission risk and infection control in a hospital emergency department in Lima. Peru Int J Tuberc Lung Dis 2010;14:1120-6.

[23] Hong M-Y, Lee CC, Chuang MC, Chao SC, Tsai MC, Chi CH. Factors related to missed diagnosis of incidental scabies infestations in patients admitted through the emergency department to inpatient services. Acad Emerg Med 2010;17:958-64.

[24] Shaw K. The 2003 SARS outbreak and its impact on infection control practices. Public Health 2006;120:8-14.

[25] Sissolak D, Bamford CM, Mehtar S. The potential to transmit Mycobacterium tuberculosis at a South African tertiary teaching hospital. Int J Infect Dis 2010;14:e423-8.

[26] Sissolak D, Marais F, Mehtar S. TB infection prevention and control experiences of South African nurses - a phenomenological study. BMC Public Health $2011 ; 11: 262$.
[27] Vardy J, Love AJ, Dignon N. Outbreak of acute gastroenteritis among emergency department staff. Emerg Med J 2007;24:699-702.

[28] Turnberg W, Daniell W, Seixas N, Simpson T, Van Buren J, Lipkin E, et al. Appraisal of recommended respiratory infection control practices in primary care and emergency department settings. Am J Infect Control 2008;36:268-75.

[29] Spector J, Rathlev NK. Pertussis in an elderly Asian-American man: a case report. J Emerg Med 2010;38:434-8.

[30] Cruz AT, Ong LT, Starke JR. Emergency department presentation of children with tuberculosis. Acad Emerg Med 2011;18:726-32.

[31] Brouqui P, Puro V, Fusco FM, Bannister B, Schilling S, Follin P, et al. Infection control in the management of highly pathogenic infectious diseases: consensus of the European Network of Infectious Disease. Lancet Infect Dis 2009;9:301-11.

[32] Busta JL, Stapleton SJ. A 37-year-old man with confusion, rash, and severe leg pain. J Emerg Nurs 2006;32:249-51.

[33] Casey ML, Chasens ER. Community-associated methicillin-resistant Staphylococcus aureus: implications for emergency department nursing. J Emerg Nurs 2009;35:224-9, quiz 272.

[34] Wallin TR, Hern HG, Frazee BW. Community-associated methicillin-resistant Staphylococcus aureus. Emerg Med Clin N Am 2008;26:431-55, ix.

[35] Cieslak TJ, Henretig FM. Medical consequences of biological warfare: the ten commandments of management. Mil Med 2001;166:11-2.

[36] Pigott DC. Emergency department evaluation of the febrile traveler. J Infect 2007;54:1-5.

[37] Rothman RE, Irvin CB, Moran GJ, Sauer L, Bradshaw YS, Fry RB, et al. Respiratory hygiene in the emergency department. Ann Emerg Med 2006;48:570-82.

[38] Siow S, Bryce EA, Scharf S. Health care workers' perceptions of respiratory and gastrointestinal algorithms for patient management in emergency care settings. Am J Infect Control 2009;37:759-65.

[39] Stirling B. Nurses and the control of infectious diseases: understanding epidemiology and disease transmission is vital to nursing care. Can Nurse 2004;100:16-20.

[40] Chege F, Cronin G. Emergency care staff can improve survival rates from sepsis. Accid Emerg Nurs 2007;15:157-60.

[41] Baka A, Fusco F, Puro V, Vetter N, Skinhoj P. A curriculum for training healthcare workers in the management of highly infectious diseases. Euro Surveill 2007;12:E5-6.

[42] Fry M, Horvat L, Roche M, Fong J, Plowes J. The prevalence and triage characteristics of patients presenting with infection to one tertiary referral hospital. Australas Emerg Nurs J 2012;15:127-32.

[43] Mackey JE, Wojcik S, Long R, Callahan JM, Grant WD. Predicting pertussis in a pediatric emergency department population. Clin Pediatr (Phila) 2007;46:437-40.

[44] Carrico RM, Coty MB, Goss LK, Lajoie AS. Changing health care worker behavior in relation to respiratory disease transmission with a novel training approach that uses biosimulation. Am J Infect Control 2007;35:14-9.

[45] Anathallee M, Curphey A, Beeching N, Carley S, Crawford I, Mackway-Jones K. Emergency departments (EDs) in the United Kingdom (UK) are not prepared for emerging biological threats and bioterrorism. J Infect 2007;54:12-7.

[46] Martel J, Bui-Xuan EF, Carreau AM, Carrier JD, Larkin E, Vlachos-Mayer H, et al. Respiratory hygiene in emergency departments: compliance, beliefs, and perceptions. Am J Infect Control 2013;41:14-8.

[47] May L, Lung D, Harter K. An intervention to improve compliance with transmission precautions for influenza in the emergency department: successes and challenges. J Emerg Med 2012;42:79-85.

[48] Dara J, Dowling JN, Travers D, Cooper GF, Chapman WW. Evaluation of preprocessing techniques for chief complaint classification. J Biomed Inform 2008;41:613-23.

[49] Chapman WW, Dowling JN, Wagner MM. Fever detection from free-text clinical records for biosurveillance. J Biomed Inform 2004;37:120-7.

[50] Rottman SJ, Shoaf KI, Schlesinger J, Selski EK, Perman J, Lamb K, et al. Pandemic influenza triage in the clinical setting. Prehosp Disaster Med 2010;25:99-104.

[51] Gerbier-Colomban S, Gicquel Q, Millet AL, Riou C, Grando J, Darmoni S, et al. Evaluation of syndromic algorithms for detecting patients with potentially transmissible infectious diseases based on computerised emergency-department data. BMC Med Inform Decis Mak 2013;13:101.

[52] Gerbier S, Yarovaya O, Gicquel Q, Millet AL, Smaldore V, Pagliaroli V, et al. Evaluation of natural language processing from emergency department computerized medical records for intra-hospital syndromic surveillance. BMC Med Inform Decis Mak 2011;11:50.

[53] Carrico R, Goss L. Syndromic surveillance: hospital emergency department participation during the Kentucky Derby Festival. Disaster Manag Response 2005;3:73-9.

[54] Moore C. Point-of-care tests for infection control: should rapid testing be in the laboratory or at the front line? J Hosp Infect 2013;85:1-7.

[55] Mills JM, Harper J, Broomfield D, Templeton KE. Rapid testing for respiratory syncytial virus in a paediatric emergency department: benefits for infection control and bed management. J Hosp Infect 2011;77:248-51.

[56] Ludwig K. Using pop culture to teach biomechanics. J Phys Educ Recreat Danc 2012;83:27-30.

[57] Rogers TB, Kuiper NA, Kirker WS. Self-reference and the encoding of personal information. J Pers Soc Psychol 1977;35:677-88. 